\title{
Machine Learning Based PEVs Load Extraction and Analysis
}

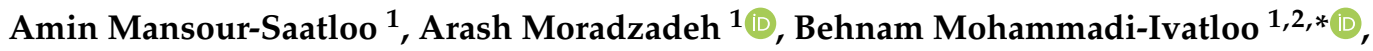 \\ Ali Ahmadian ${ }^{3,4, *}$ and Ali Elkamel 4,5 \\ 1 Faculty of Electrical and Computer Engineering, University of Tabriz, Tabriz 5166616471, Iran; \\ amin_mnsr97@ms.tabrizu.ac.ir (A.M.-S.); arash.moradzadeh@tabrizu.ac.ir (A.M.) \\ 2 Institute of Research and Development, Duy Tan University, Da Nang 550000, Vietnam \\ Department of Electrical Engineering, University of Bonab, Bonab 5551761167, Iran \\ College of Engineering, University of Waterloo, Waterloo, ON N2L 3G1, Canada; aelkamel@uwaterloo.ca \\ College of Engineering, Khalifa University of Science and Technology, Abu Dhabi 127788, UAE \\ * Correspondence: mohammadi@ieee.org (B.M.-I.); ali.ahmadian@uwaterloo.ca (A.A.)
}

Received: 4 July 2020; Accepted: 14 July 2020; Published: 16 July 2020

check for updates

\begin{abstract}
Transformation of the energy sector due to the appearance of plug-in electric vehicles (PEVs) has faced the researchers with challenges in recent years. The foremost challenge is uncertain behavior of a PEV that hinders operators determining a deterministic load profile. Load forecasting of PEVs is so crucial in both operating and planning of the energy systems. PEV load demand mainly depends on traveling behavior of them. This paper tries to present an accurate model to forecast PEVs' traveling behavior in order to extract the PEV load profile. The presented model is based on machine-learning techniques; namely, a generalized regression neural network (GRNN) that correlates between PEVs' arrival/departure times and traveling behavior is considered in the model. The results show the ability of the GRNN to communicate between arrival/departure times of PEVs and the distance traveled by them with a correlation coefficient (R) of $99.49 \%$ for training and $98.99 \%$ for tests. Therefore, the trained and saved GRNN model is ready to forecast PEVs' trip length based on training and testing with historical data. Finally, the results indicate the importance of implementing more accurate methods to predict PEVs to gain the significant advantages in the importance of electrical energy in vehicles in the years to come.
\end{abstract}

Keywords: plug-in electric vehicle (PEV); load forecasting; machine learning; generalized regression neural network (GRNN)

\section{Introduction}

Among the most energy consumers in the world, which can be divided into four sectors, i.e., transportation, industry, commerce and residence [1], the transportation sector delivers the most greenhouse gases, nearly 50\%, into the atmosphere, causing air pollution, climate change and global warming [2]. Transportation electrification is a feasible opportunity to stop the mass motorization of the transportation sector and consequently reduce greenhouse gas emissions. However, on the other hand, the advent of plug-in electric vehicles (PEVs) exposes new challenges that must be discussed from the power system point of view [3]. The most important challenge toward PEVs is the power-delivery issue to the storage system of them [4].

PEVs' charging issue due to weak distribution infrastructures in many countries and an increasing number of PEV fleets is one of the research topics in recent years. For instance, PEV aggregators have been proposed in [5] to handle the coordinated PEV charging. Another solution is battery-swapping technology that was proposed in [6,7]. The uncertainty of the load profile of PEVs is one of the main 
issues in the operation of PEV-integrated systems [8]. For optimal scheduling of the power grid in order to avoid stresses from high penetration of PEVs, the load profile of PEVs can be forecasted. In doing so, transmission and distribution operators know how much power is expected for the charging of PEVs and can take appropriate strategies. PEV load demand mainly depends on its battery capacity, battery efficiency and traveling distance. Details of the most popular EV models can be found in [9]. For instance, a Nissan Leaf's battery capacity is $30 \mathrm{kWh}$, which means nearly four times more than a residential building's demand is required.

So far, much of the literature has tried to forecast the load profile of EVs using different techniques. Generally, these techniques can be divided into four categories: 1-Probabilistic-based methods: a stochastic model of the plug-in EVs (PEVs) to extract PEV load demand considering nonlinearity of the battery behavior in charging mode has been proposed in [10]. A stochastic method for day-ahead scheduling considering the uncertainty of EVs' load has been presented in [11]. A stochastic-scheduling model for EV charging in the domestic grid has been proposed in [12]. 2-Markov chain method: a hybrid Grey/Markov model was utilized in [13] to consider the object-principle trend and fluctuation in the load forecasting of EVs. The Markov model and the hidden Markov model have been utilized to model the EVs' traveling behavior and demand [14]. A Markov process has been applied to improve the security of supply in [15]. 3-Queuing theory: a single-EV charging model has been developed for multiple EVs using queuing theory in [16]. In [17], the rapid-charging-station model has been formulated based on queuing theory. 4-The fourth method is based on traffic studies and origin-destination (OD) concepts [18-20]. In addition, a comprehensive review and comparison of load-modeling techniques is available in [9]. All these mentioned works suffer from considering the correlation between datasets. However, this issue can be addressed using an artificial neural network (ANN) and machine-learning methods.

Several valuable studies are available that benefit from these methods to forecast EV load profile. An artificial neural network has been utilized to forecast daily arrival time and daily traveling distance in [21], where the forecasted parameters have been used for load forecasting of PEV fleets. Feedforward and recurrent artificial neural networks were developed to forecast traveling behavior of PEVs in [22]. Another work in [23] has employed a variation of ANN, namely nonlinear autoregressive exogenous (NARX), to model the driving behavior of PEVs for long-term estimation. A data-mining approach has been applied to analyze household charging patterns of PEVs in [24], where utilized data was collected based on advanced metering infrastructure (AMI). Different machine-learning methods, including recurrent neural network (RNN) and long short term memory (LSTM), have been compared in the application of PEV-charging-load forecasting in [25]. In the same way, mixed integer linear programming (MILP) and RNN have been compared in [26] for optimal planning of PEVs' charging and discharging. ANN can consider the correlation between datasets but is still poor from the accuracy point of view in the comparison of machine-learning techniques. This paper aims to forecast the EV load profile based on machine-learning techniques, namely, a generalized regression neural network (GRNN). GRNN is one of the popular techniques that has a wide range of applications in different research areas, e.g., physical-health evaluation [27], medical science [28], power system study [29], etc.

According to the reviewed literature and to the best of the authors' knowledge, there is a lack of study toward machine learning's powerful techniques in PEV-load-profile forecasting. Therefore, the current paper tries to fill this research gap by employing the GRNN method. Indeed, machine learning is a subcategory of artificial intelligence, including special patterns and statistical models in which machines perform work by recognizing them without interacting with a user.

The rest of the paper is organized as follows: Section 2 describes the adopted methodology. Section 3 provides results and discussions to verify the proposed methodology. Finally, Section 4 concludes the paper.

\section{Methodologies}

This section presents a description of the GRNN method and PEV-battery model. 


\subsection{Generalized Regression Neural Network (GRNN)}

GRNN is one of the machine-learning applications and a powerful regression model. GRNN can be defined as a type of radial-basis-function (RBF) network that has a very high training speed based on a completely parallel structure. Even with low input data, this network is able to establish nonlinear relationships between the target variable and a set of independent variables [30,31]. Fast learning, meaningful communication between target time-series data and a set of explanatory variables and rapid convergence to optimal regression levels with an increasing number of samples are the most important advantages of GRNN [32,33]. As Figure 1 shows, the input layer, the pattern layer, the summation layer and the output layer form the GRNN structure [34].

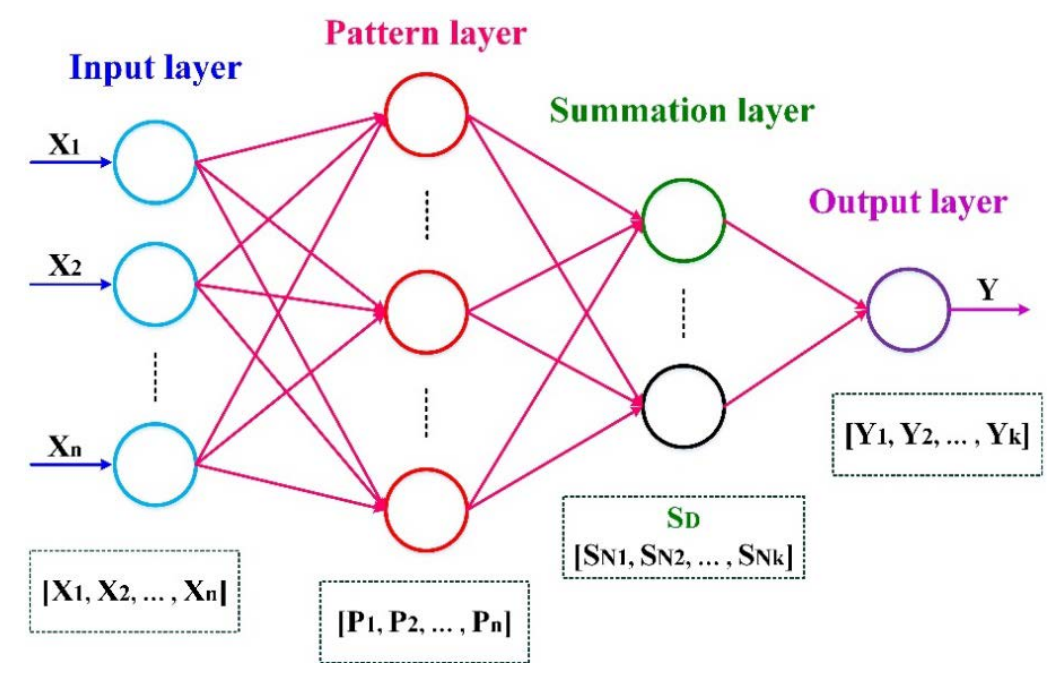

Figure 1. Basic structure of generalized regression neural network (GRNN).

The inputs of Figure 1 include all the parameters that are effective in determining and predicting the output. In this paper, the arrival and departure times of the EVs are considered as the inputs, and the traveling distances by each EV are forecasted as the output of the GRNN. The input layer does not contain any processing and just transfers the input data to the next layer. The pattern layer determines the number of neurons by the training data and includes the following function [34]:

$$
p_{i}=\exp \left[-\frac{\left(X-X_{i}\right)^{T}}{2 \sigma^{2}}\right] ; i=1,2, \ldots, N
$$

where $X$ shows the network input variable, $X_{i}$ depicts the training sample related to the neuron $i$, $T$ demonstrates the transpose symbol and $\sigma$ is the smoothing parameter. The more $\sigma$ is made large, the smoother the estimated density that can be reached.

The output of neuron $i$ is defined as

$$
D_{i}^{2}=\left(X-X_{i}\right)^{T}\left(X-X_{i}\right)
$$

The summation layer includes two types of summation. The first case in which the arithmetic summation of all neurons can be calculated is expressed according to the following relation, and its output is defined as (4) [30,34]:

$$
\begin{gathered}
\sum_{i=1}^{N} \exp \left[-\frac{\left(X-X_{i}\right)^{T}\left(X-X_{i}\right)}{2 \sigma^{2}}\right] \\
S_{D}=\sum_{i=1}^{N} p_{i}
\end{gathered}
$$


The second summation is obtained as follows:

$$
\sum_{i=1}^{N} Y_{i} \exp \left[-\frac{\left(X-X_{i}\right)^{T}\left(X-X_{i}\right)}{2 \sigma^{2}}\right]
$$

where $Y_{i}$ is the $i$ th connection weight, and the second output is determined as follows:

$$
S_{N j}=\sum_{i=1}^{N} y_{i j} p_{i} ; j=1,2, \ldots, k
$$

Finally, in the output layer, the probable value of the output $y(x)$ is obtained by dividing the weighted summation by the arithmetic summation as follows [32,34]:

$$
y_{j}=\frac{S_{N j}}{S_{D}} ; j=1,2, \ldots, k
$$

In the GRNN structure, the summation neurons $S_{N 1}$ calculate the sum of the weighted outputs of the pattern layer, while $S_{N 1}$ computes the unweighted outputs of the pattern neurons. The output layer divides the output of the $\mathrm{S} 1$ neuron by the output of the $S_{N 2}$ neuron to yield the desired estimate [35]. Figure 2 illustrates the flowchart of the GRNN.

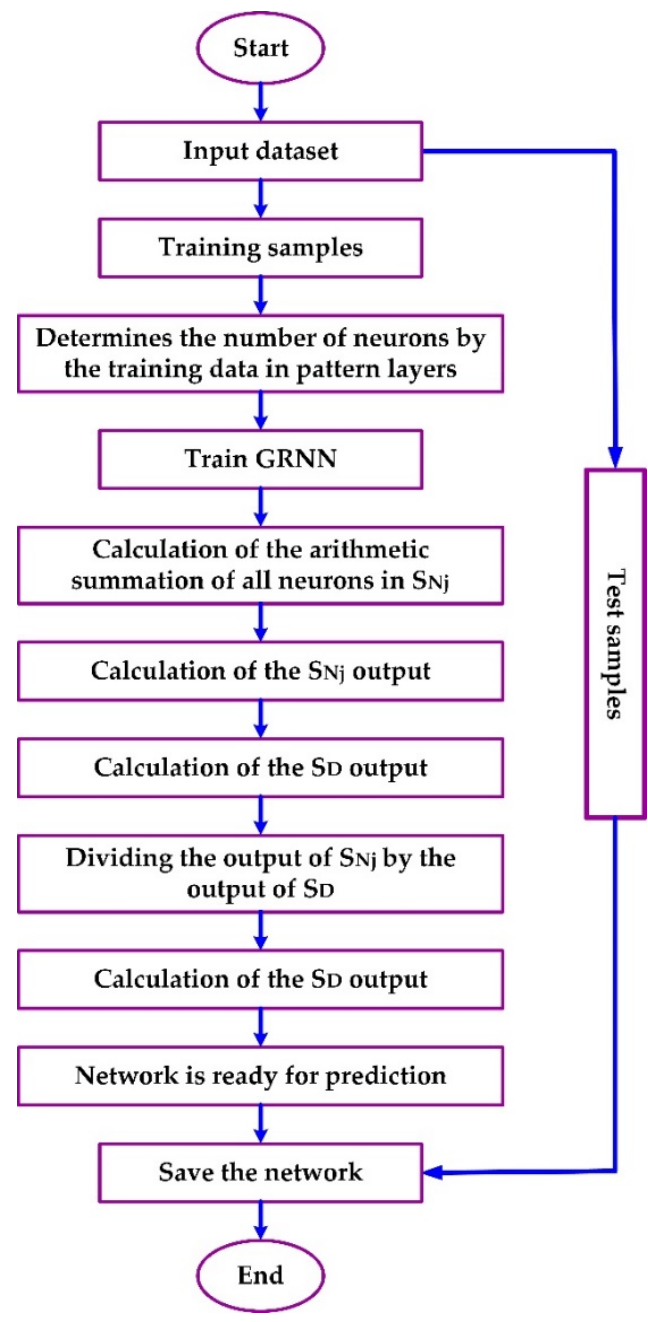

Figure 2. Principle flowchart of the GRNN model. 


\subsection{Battery SoC Model}

Each EV uses a battery as an energy-storage system. In this paper, the lithium-ion battery also is selected for each EV. The state of charge (SoC) of a battery can be modeled as a nonlinear function or linear function [10]. However, most of the nonlinear models are developed via empirical-based models that are not proper for optimal power-system research. Therefore, in this work, because of the simplicity, a linear model of the SoC calculation is adjusted like many of the other works $[9,14]$. A linear form of the SoC can be stated as below:

$$
\operatorname{SoC}_{i}^{t}=\operatorname{SoC}_{i}^{t-1}+\frac{\eta_{i}^{c h r} \times P^{c h r, t}}{C a p_{i}} \times 100
$$

where $\operatorname{SoC}_{i}^{t}(\%)$ is the $S o C$ of the $i$ th $\mathrm{EV}$ at time $t, \eta_{i}^{c h r}$ is the charging efficiency of each EV, Cap $p_{i}$ is the capacity of EVs and $P^{c h r, t}(\mathrm{~kW})$ is the charging power at time $t$. At the beginning of the charging process, the initial SoC of the EV must be known and can be extracted from Equation (10).

$$
\operatorname{SoC}_{i}^{\text {int }}=\left(1-\frac{\rho_{i}^{d i s} \times d_{i}}{\text { Capi }_{i}}\right) \times 100
$$

In Equation (10), $S o C_{i}^{\text {int }}(\%)$ is the initial $S o C$ of each $\mathrm{EV}, d_{i}($ mile $)$ is the traveling distance and $\rho_{i}^{\text {dis }}(\mathrm{kWh} / \mathrm{mile})$ is the efficiency of discharging.

\section{Performance Evaluation of GRNN}

Evaluating the performance of each study is considered the most important part. With this evaluation, the results of each study can be verified. Evaluating and ensuring the performance of results can be done in a variety of ways [36]. In this paper, the correlation coefficient (R), mean square error (MSE), root-mean-square error (RMSE) and mean absolute error (MAE) were used as statistical performance criteria to evaluate the performance of the GRNN method. Each of these criteria provides unique analysis and evaluation. Therefore, the highest value of $\mathrm{R}$ to 1 and the lowest values for MSE and RMSE to zero indicate the best network performance. Each of these statistical performance criteria can be calculated as follows $[37,38]$ :

$$
\begin{gathered}
R=\frac{\sum_{l=1}^{N}\left(x_{l}-\bar{x}\right)\left(y_{l}-\bar{y}\right)}{\sqrt{\sum_{l=1}^{N}\left(x_{l}-\bar{x}\right)^{2} \sum_{l=1}^{N}\left(y_{l}-\bar{y}\right)^{2}}} \\
R M S E=\sqrt{\frac{1}{N} \sum_{l=1}^{N}\left(x_{l}-y_{l}\right)^{2}} \\
M S E=\frac{1}{N} \sum_{l=1}^{N}\left(x_{l}-y_{l}\right)^{2} \\
M A E=\frac{1}{N} \sum_{l=1}^{N}\left|x_{l}-y_{l}\right|
\end{gathered}
$$

where $X_{i}$ and $\bar{X}$ show the real value and average of real values and $Y_{i}$ and $\bar{Y}$ are the forecasted value and average of forecasted values, respectively. 


\section{Simulation Results}

Utilizing machine-learning applications requires a database. The dataset used in this paper is related to historical and real-world data and has been presented in the supporting materials of the reference [9]. This dataset includes three parameters: arrival time, departure time and traveling distance of 500 EVs in the real world. Figure 3 depicts arrival and departure times for the dataset. Actually, traveling distance had a correlation with arrival/departure time and can be estimated by knowing arrival/departure times. This prediction was made by GRNN. Using this method requires a database as input. The arrival/departure times for each EV were collected and utilized as the input dataset, and traveling distance for each EV was selected as the target for the GRNN. In this work, $80 \%$ of this dataset was used for training the system, and the last $20 \%$ was used for verifying the efficiency of the system in forecasting traveling distance. The review of the employed algorithm is given in Figure 4. All the provided simulations were developed in MATLAB 2018b environment on a PC with an Intel Core i7 processor with $2.50 \mathrm{GHz}$ and $8 \mathrm{~GB}$ of RAM.

Figure 5 shows the correlation coefficient between the input and output variables for the training phase. Figure 6 illustrates the performance of the network in the form of MSE in the training phase. The results provided for training indicated good correlation of the network, with $\mathrm{R}=99.49 \%$ accuracy at this stage. Figures 7-9 also show the results of the R, MSE and RMSE errors and the error histogram in the test phase, respectively.

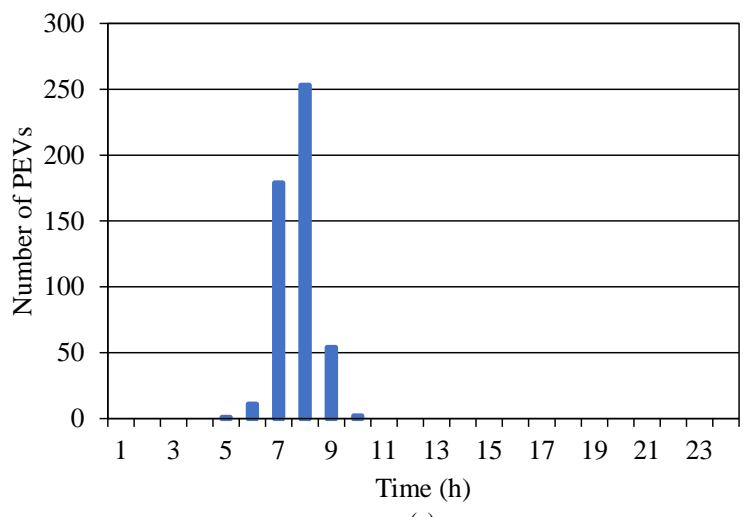

(a)

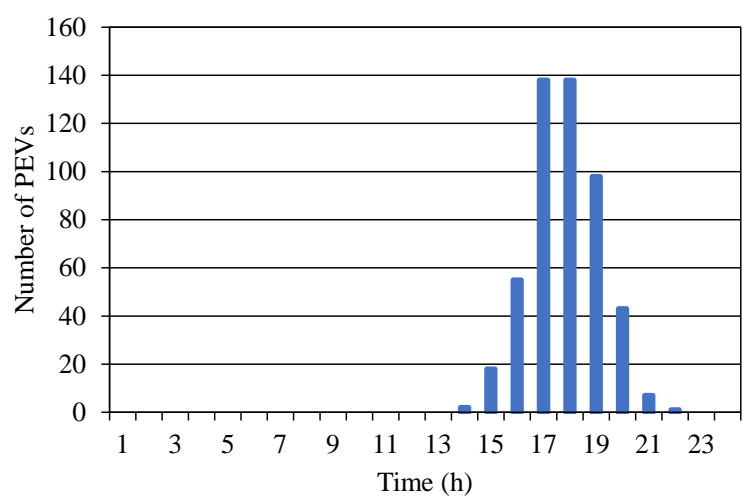

(b)

Figure 3. (a) Pattern of departure time. (b) Pattern of arrival time. 


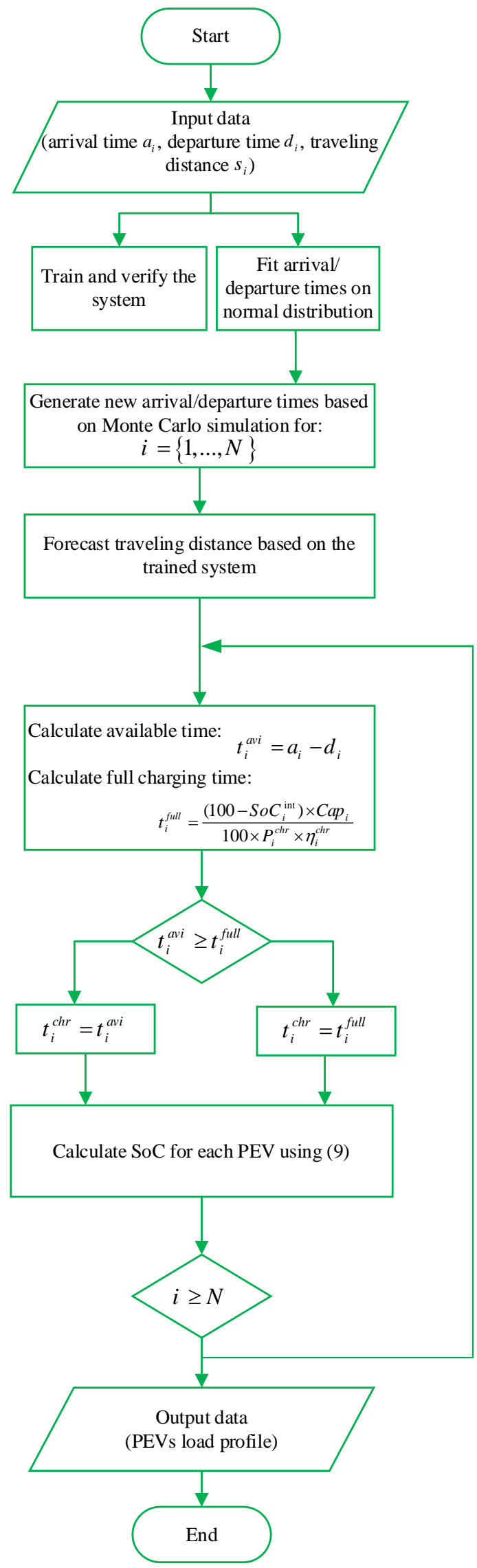

Figure 4. The review of the employed algorithm. 


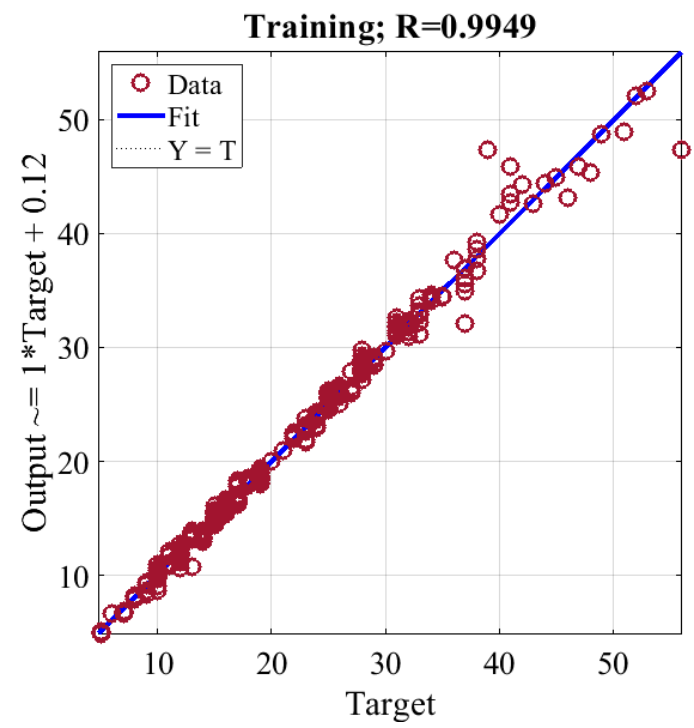

Figure 5. Correlation coefficient for the training phase.

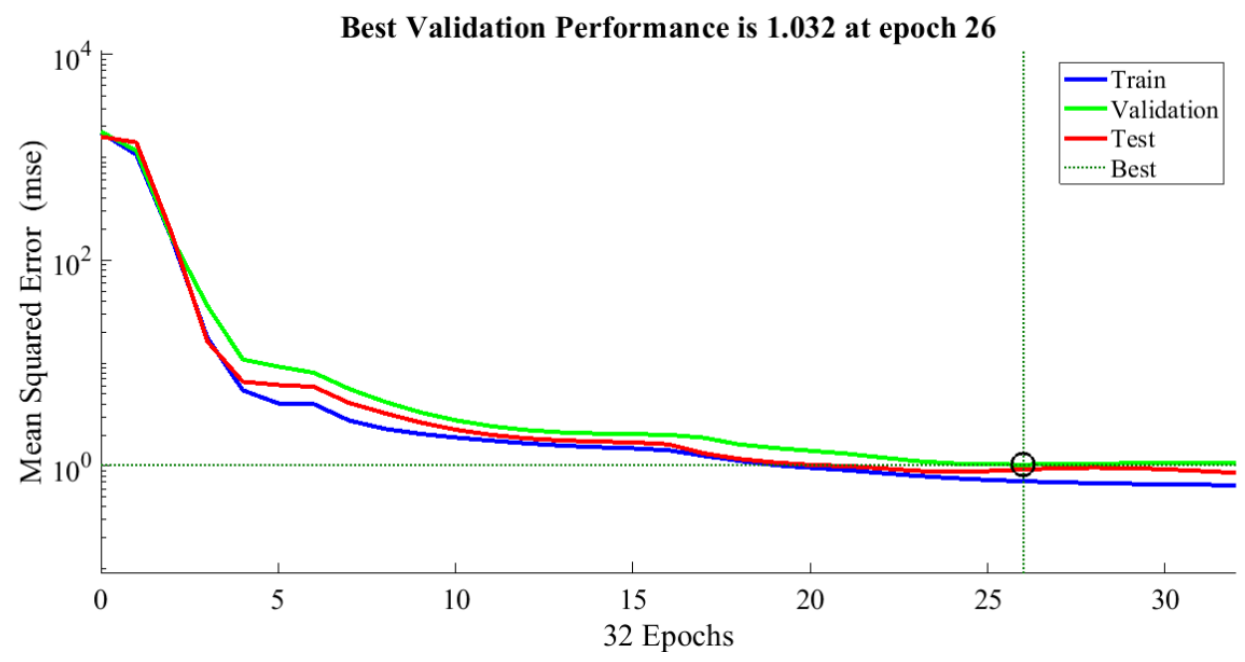

Figure 6. Performance of the GRNN network in the form of mean square error (MSE).

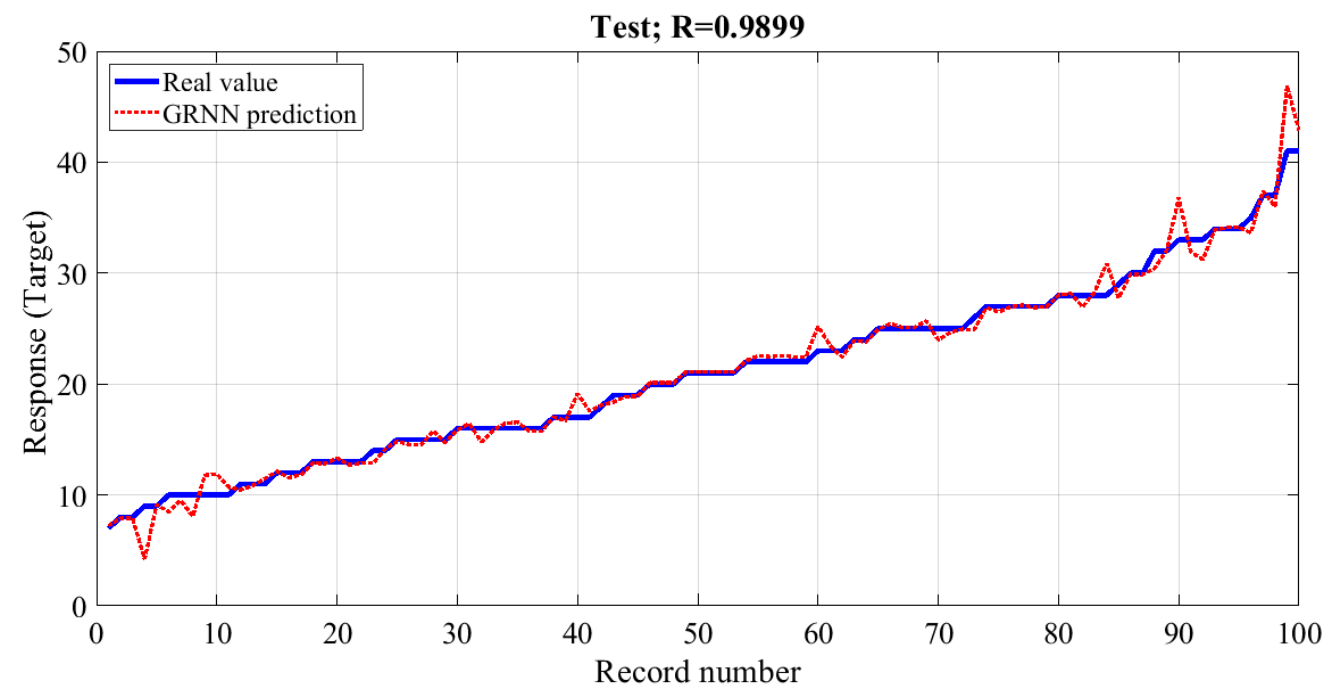

Figure 7. Prediction of GRNN for test data. 


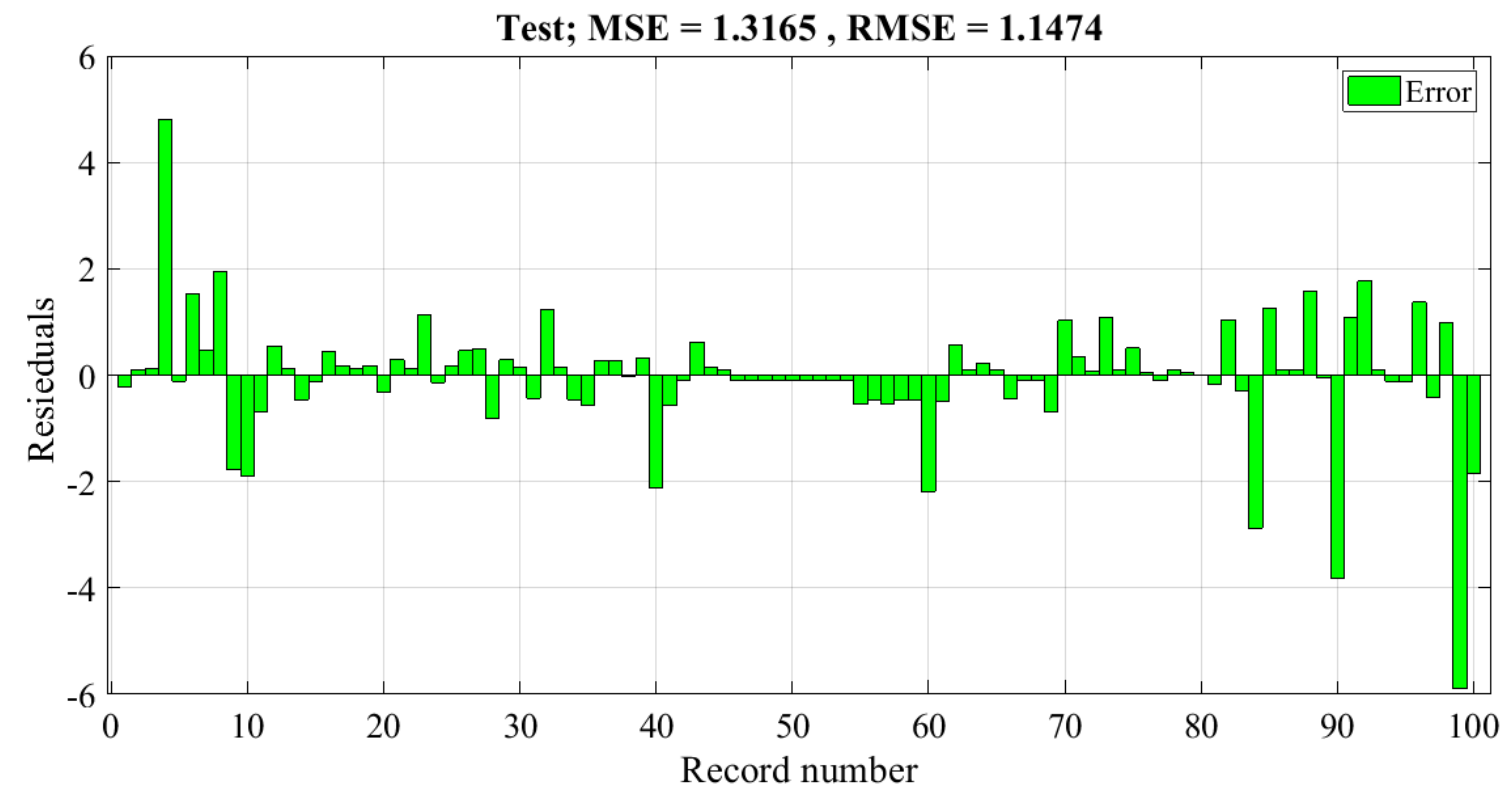

Figure 8. Network test errors in the form of MSE and root-mean-square error (RMSE).

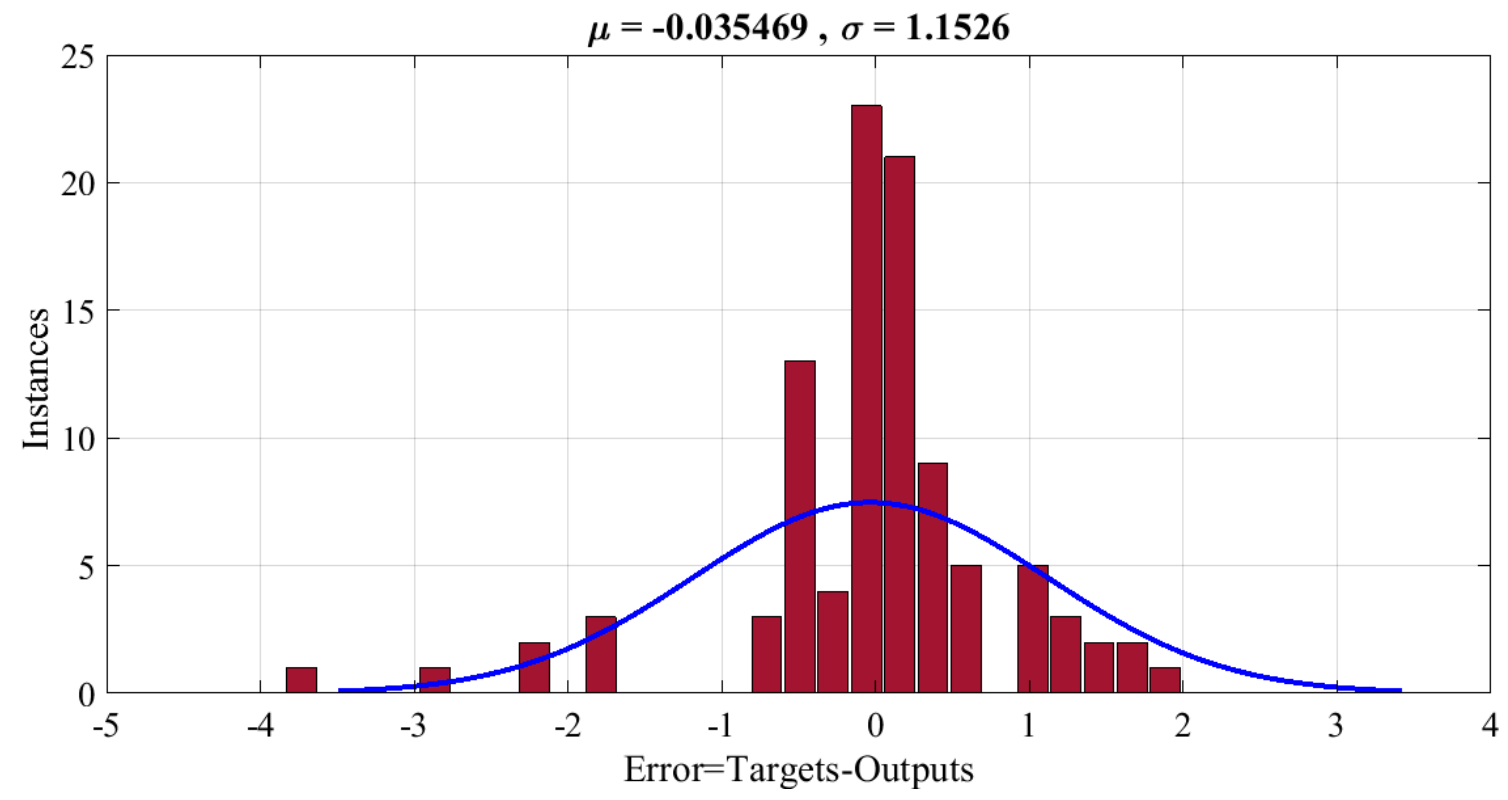

Figure 9. Network test error in the form of histogram.

The results presented in Figures 7-9 guaranteed the validation and accuracy of the training phase for predicting new input samples. After training and validation, the network could be saved as a black box and used to identify new data.

Then, arrival/departure times were fitted on a normal distribution, and 500 new arrival/departure datapoints were generated using the Monte Carlo simulation. It should be noted that in the literature, usually normal distribution was used to model the arrival/departure times [13]. Hence, normal distribution was employed in this work. The produced new dataset was utilized as inputs of the trained and saved network to forecast new traveling distances. This process was repeated 200 times to generate different scenarios. Figure 10 shows arrival and departure times for the generated new dataset for two of the scenarios. All of the PEVs were assumed to have a lithium-ion battery with the capacity of $30 \mathrm{kWh}$, charging efficiency of 0.88 and discharging efficiency of $0.28 \mathrm{kWh} / \mathrm{mile}$. 


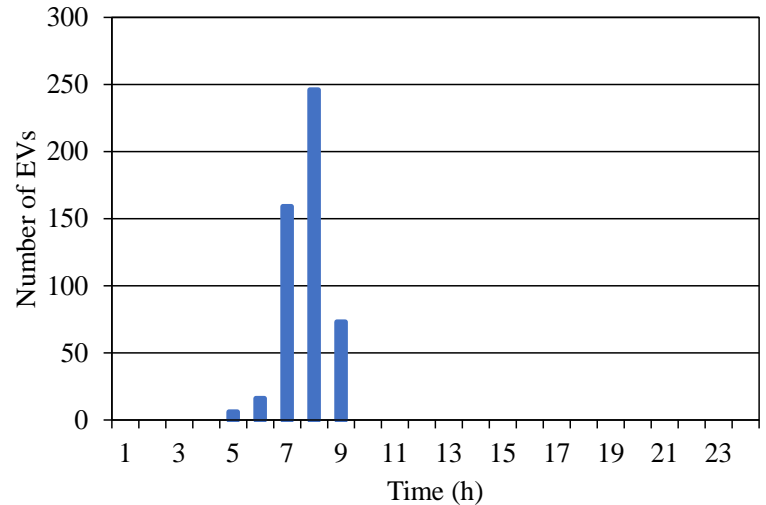

(a)

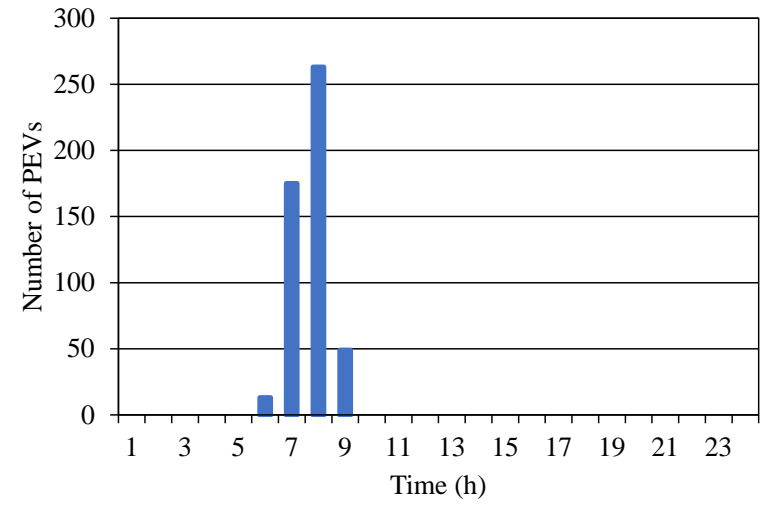

(b)

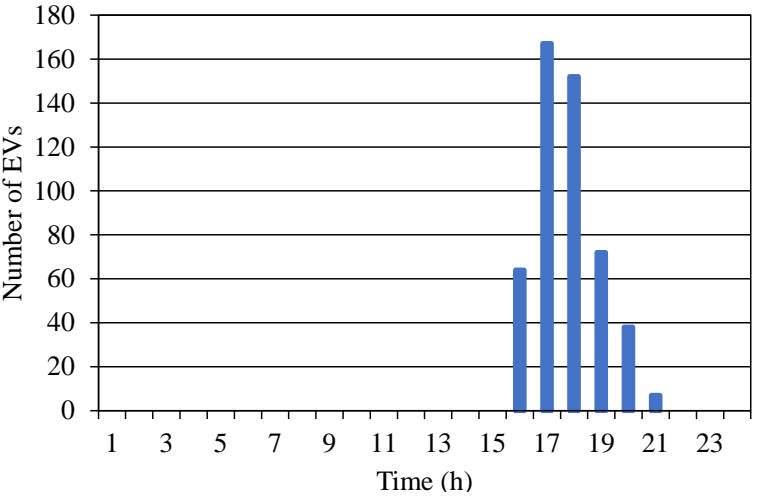

(c)

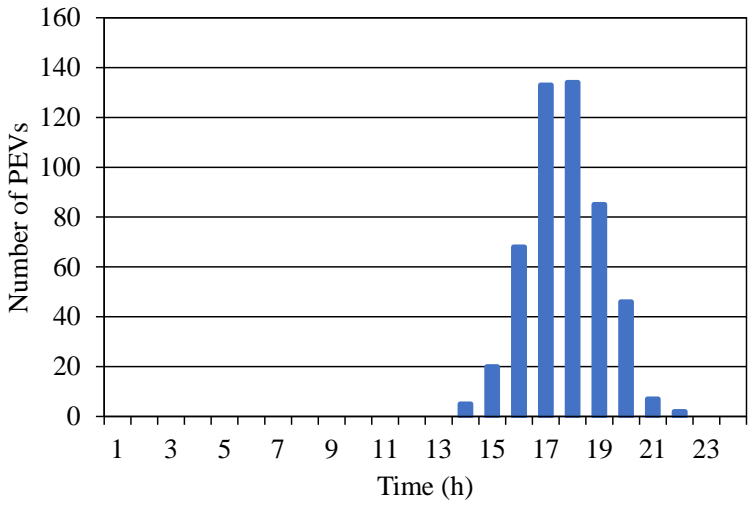

(d)

Figure 10. Pattern of generated departure times for (a) first scenario and (b) second scenario; pattern of generated arrival times for (c) first scenario and (d) second scenario.

PEVs start to be charged with rated power after arriving at the parking spot until the charging time has elapsed. Charging time of each PEV depends on its initial SoC at the arrival time. The initial $\mathrm{SoC}$ for the whole of the PEVs for different scenarios is depicted in Figure 11. It can be seen that most of the PEVs arrived at the parking spot with more than $50 \%$ SoC, i.e., more than $15 \mathrm{kWh}$ of energy. Simultaneously with the PEVs' arrival time, residential homes' demand started to rise. A traditional home load profile is provided in Figure 12. A comparison of Figures 11 and 12 indicates that PEVs have great potential to help the peak shaving of residential homes in the way of discharging at the on-peak hours, i.e., $t=18: 00$ to $t=00: 00$, and then starting to charge at 01:00 until departure time. The main concern here is maybe that available time from 01:00 until PEVs' departure time is not enough to charge the PEVs up to an appropriate level that meets their daily traveling-distance requirement. For a residential home, the charging level is $1.5 \mathrm{kWh}$. Let us assume that each PEV starts to be charged instantly after arriving home with the $1.5 \mathrm{kWh}$ rating power. Figure 13a shows the load profile of whole PEVs for different scenarios with the $1.5 \mathrm{kWh}$ charging rate. In addition, load profiles of five different PEVs for two different scenarios are shown in Figure 7. According to Figure 14a, EV number 1's, 2's, 3's and 5's demand at the final hour of the charging period was a fraction of rated power due to their demand being fully met and their battery that could be fully charged before leaving the parking spot. This means that their available time for charging was enough to charge their battery up to $100 \%$. However, EV number 4 could not be fully charged because of the lack of available time, and it charged with the rated power until it left the parking spot. Figure 13a shows that from the PEVs' arrival times $(t=15: 00)$, the load profile had ascending behavior with the increasing number of PEVs, where the peak load occurred at time $t=23$, when almost all PEVs were plugged into the grid, and $750 \mathrm{~kW}$ of power was required at that time. Then, from the hour $t=08: 00$, PEVs left the parking spots and the load profile had descending behavior. In total, nearly $6.8 \mathrm{MWh}$ of energy was required to meet PEVs' demand in one day. According to this analysis with the low charging rate, it was not feasible to 
utilize PEVs as a storage system that can help peak shaving of residential homes. To do so, a higher level of charging rate is required. Figure 13b,c shows the load profile of PEVs with higher charging levels. Table 1 describes adopted charging levels. The more the charging rate rose, the more energy was required at peak hours. In the case of II and III charging levels, 1.5 MWh and 1.7 MWh of energy were required at peak hours, which can cause bus-voltage drops and line-current violations. Therefore, an accurate model for PEV load profile is very necessary to optimally schedule the system in order to benefit from the great potential of PEVs from the power system and environmental points of view.
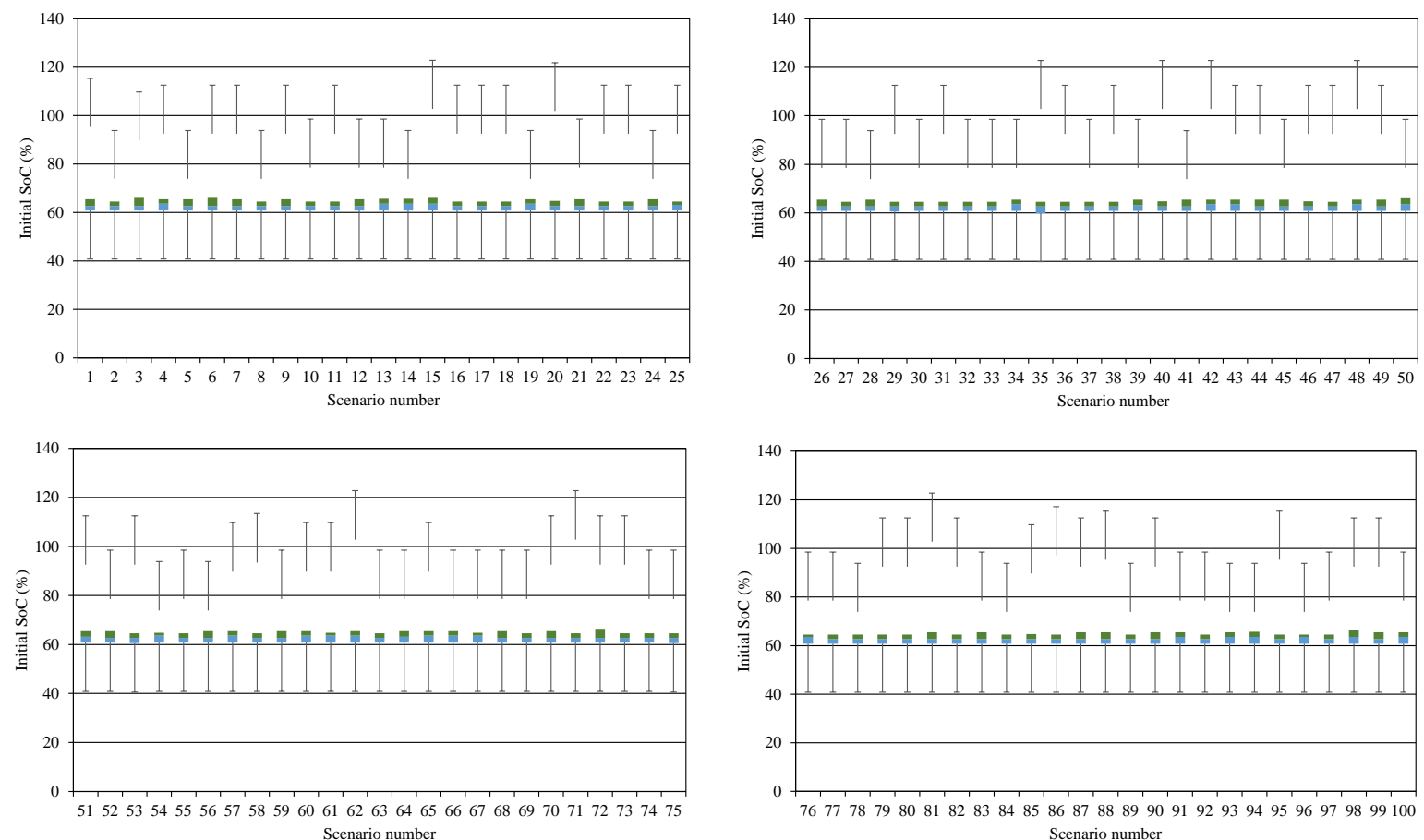

Figure 11. Initial state of charge (SoC) for different scenarios.

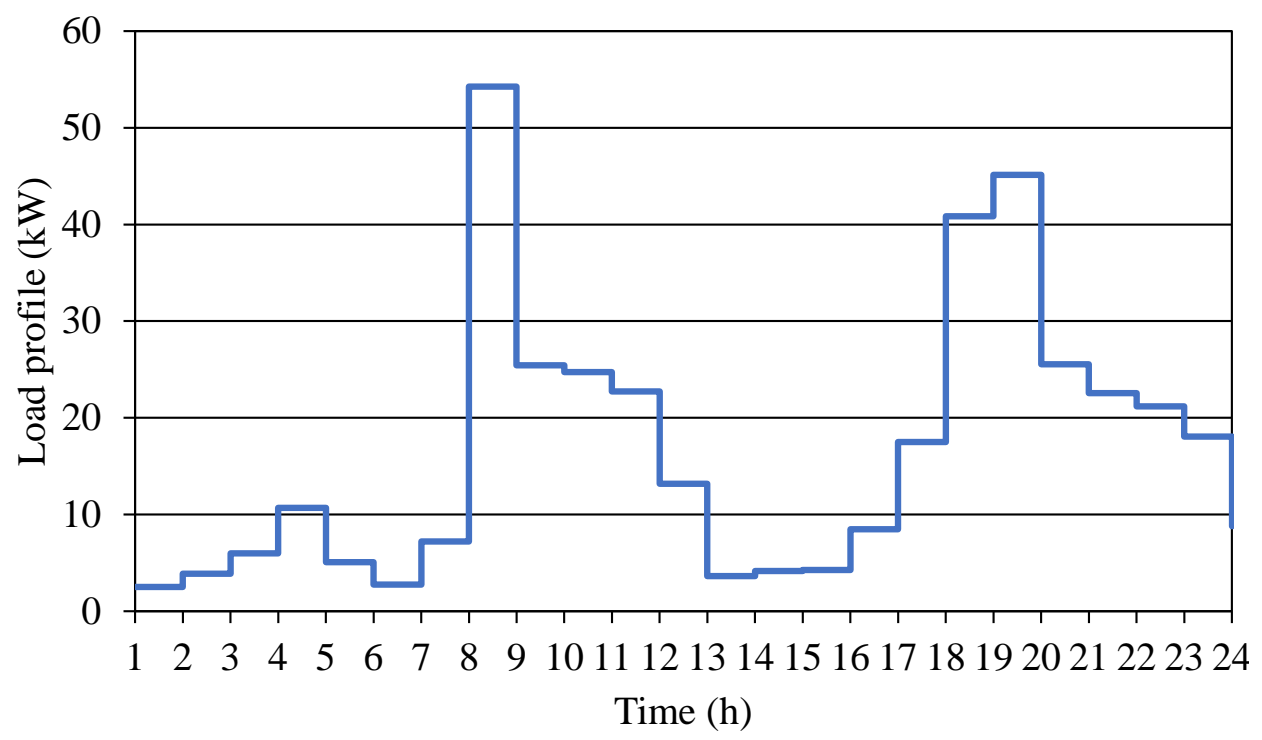

Figure 12. Traditional home load profile. 


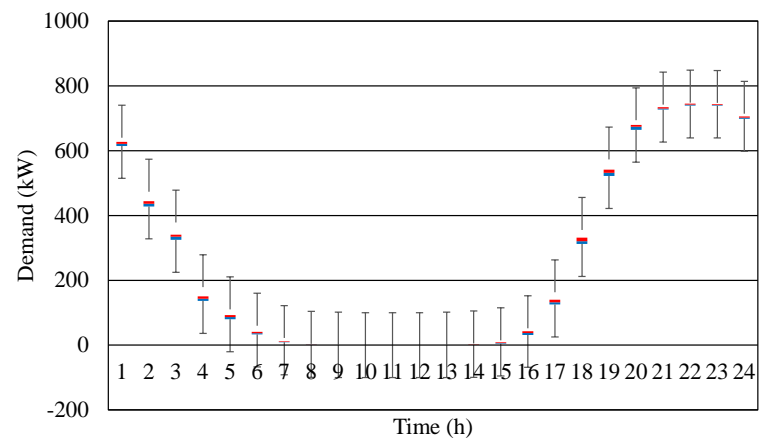

(a)

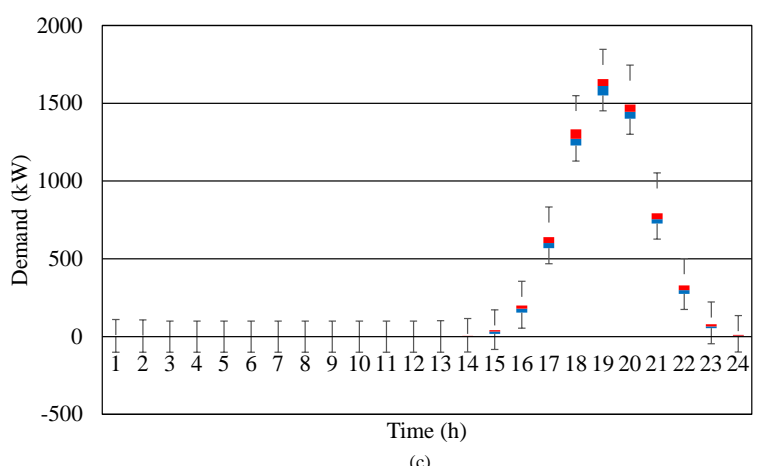

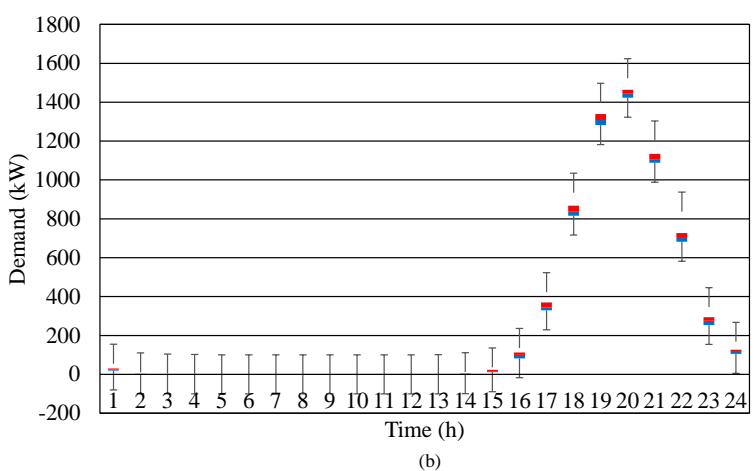

Figure 13. Plug-in electric vehicle (PEV) total load profile for (a) charge level I, (b) charge level II and (c) charge level III.

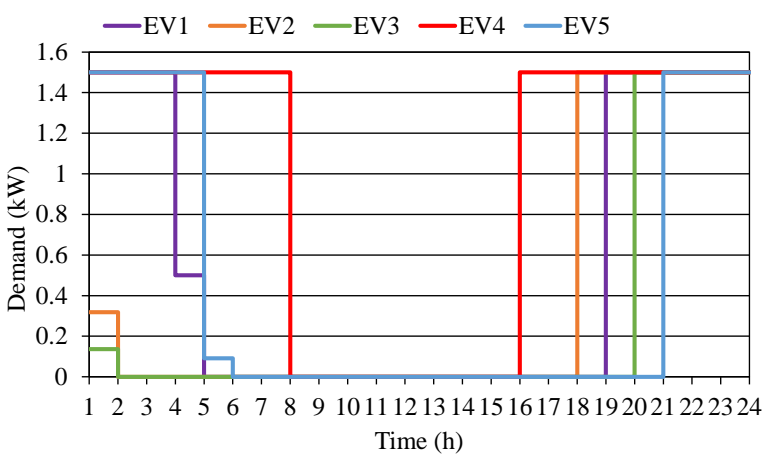

(a)

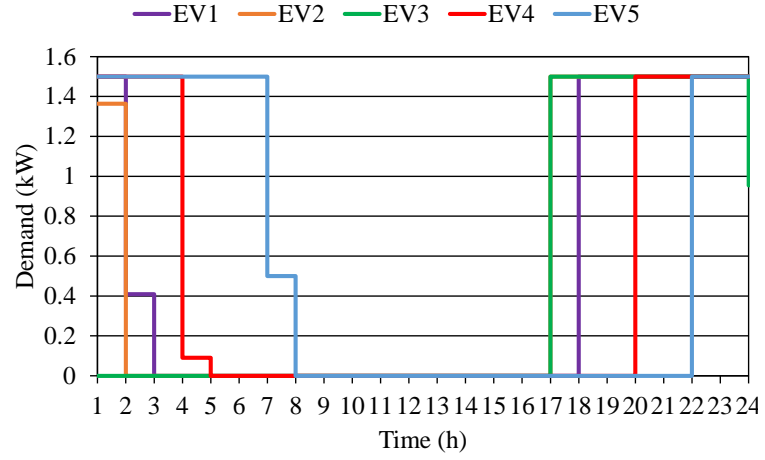

(b)

Figure 14. Individual PEV load profile in (a) first scenario and (b) second scenario.

Table 1. PEV charging power level.

\begin{tabular}{cc}
\hline Charging Level & Selected Charging Level (kW) \\
\hline Level I & 1.5 \\
\hline Level II & 4 \\
\hline Level III & 8 \\
\hline
\end{tabular}

To evaluate the effectiveness of the GRNN in traveling-distance prediction, a comparison should be made with the results obtained from other methods. The results should be compared for the same data, but research has been done in various studies using different data. Table 2 compares the results of various studies in traveling-distance prediction with the model presented in this paper. 
Table 2. Comparison of traveling-distance prediction results with other works.

\begin{tabular}{|c|c|c|c|c|}
\hline Methods & $\mathbf{R}$ & MSE & RMSE & MAE \\
\hline GRNN in this paper & 0.9899 & 1.3165 & 1.1474 & 0.8199 \\
\hline ANN [21] & - & 3.275 & 1.809 & - \\
\hline k-nearest neighbor (k-NN) [24] & 0.8928 & - & - & - \\
\hline Random forest algorithm (RFA) [24] & 0.9459 & - & - & - \\
\hline Classification and regression trees (CHART) [24] & 0.9186 & - & - & - \\
\hline Chi-square automatic interaction detector (CHAID) [24] & 0.9151 & - & - & - \\
\hline Conventional Error Back Propagation (CEBP) [22] & 0.8364 & - & 15.90 & 11.33 \\
\hline Levenberg Marquardt (LM) [22] & 0.8683 & - & 12.56 & 9.09 \\
\hline Rough based CEBP (R-CEBP) [22] & 0.8969 & - & 11.27 & 7.84 \\
\hline Rough based LM (R-LM) [22] & 0.9447 & - & 8.11 & 5.87 \\
\hline Recurrent rough network with CEBP (RR-CEBP) [22] & 0.9099 & - & 9.04 & 6.42 \\
\hline Recurrent Rough network with (RR-LM) [22] & 0.9588 & - & 8.10 & 5.48 \\
\hline
\end{tabular}

The results presented in Table 2 show that selecting the significant method can have a high impact on the results. Thus, GRNN was able to achieve the goals of the paper with good accuracy and achieve this important goal. Finally, it should be noted that the proposed solution can also be utilized for a variety of similar data in the real world.

\section{Conclusions}

Following the transformation of the energy sector and integrating plug-in vehicles (PEVs) into the energy systems, this work was conducted to alleviate some of the appeared challenges. In this paper, a novel method for PEV load forecasting for energy management of future use was presented. For this purpose, one of the machine-learning applications, called a generalized regression neural network (GRNN), was suggested. The network used historical data on the arrival/departure times of PEVs for training as long as it could estimate the distance traveled by each EV. Additionally, Monte Carlo simulation was used to expand the data based on fitting historical data, i.e., arrival/departure time, on an appropriate distribution function. After training and tests, the network was saved by learning the travel pattern associated with each EV to be used to predict the distance traveled by new EVs. The network was able to forecast new data with $98.99 \%$ accuracy, MSE $=1.3165$, RMSE $=1.1474$ and MAE $=0.8199$ errors.

This work can be extended by focusing on electrical-network constraints and investigating integrating PEV aggregators to manage the PEVs' demand. In addition, smart charging of PEVs can be taken into account to model the PEVs with more details.

Author Contributions: Data curation, A.M.-S. and A.M.; Formal analysis, A.M., B.M.-I. and A.A.; Methodology, A.M.-S. and A.E.; Software, A.M.-S. and A.M.; Validation, B.M.-I. and A.E.; Visualization, A.A.; Writing-review \& editing, A.A. and A.E. All authors have read and agreed to the published version of the manuscript.

Funding: This research received no external funding.

Conflicts of Interest: The authors declare no conflict of interest.

\section{References}

1. Dunn, D.R. US Energy Information Administration Monthly Energy Review 2016. Available online: https: //www.eia.gov/totalenergy/data/monthly/ (accessed on 12 July 2020).

2. Ahmadian, A.; Sedghi, M.; Elkamel, A.; Fowler, M.; Aliakbar Golkar, M. Plug-in electric vehicle batteries degradation modeling for smart grid studies: Review, assessment and conceptual framework. Renew. Sustain. Energy Rev. 2018, 81, 2609-2624. [CrossRef]

3. Xie, S.; Hu, X.; Qi, S.; Tang, X.; Lang, K.; Xin, Z.; Brighton, J. Model predictive energy management for plug-in hybrid electric vehicles considering optimal battery depth of discharge. Energy 2019, 173, 667-678. [CrossRef] 
4. Ahmadian, A.; Sedghi, M.; Aliakbar-Golkar, M.; Fowler, M.; Elkamel, A. Two-layer optimization methodology for wind distributed generation planning considering plug-in electric vehicles uncertainty: A flexible active-reactive power approach. Energy Convers. Manag. 2016, 124, 231-246. [CrossRef]

5. Alipour, M.; Mohammadi-Ivatloo, B.; Moradi-Dalvand, M.; Zare, K. Stochastic scheduling of aggregators of plug-in electric vehicles for participation in energy and ancillary service markets. Energy 2017, 118. [CrossRef]

6. Dai, Q.; Cai, T.; Duan, S.; Zhao, F. Stochastic modeling and forecasting of load demand for electric bus battery-swap station. IEEE Trans. Power Deliv. 2014, 29, 1909-1917. [CrossRef]

7. Wang, Y.; Ding, W.; Huang, L.; Wei, Z.; Liu, H.; Stankovic, J.A. Toward urban electric taxi systems in smart cities: The battery swapping challenge. IEEE Trans. Veh. Technol. 2017, 67, 1946-1960. [CrossRef]

8. Aliasghari, P.; Mohammadi-Ivatloo, B.; Alipour, M.; Abapour, M.; Zare, K. Optimal scheduling of plug-in electric vehicles and renewable micro-grid in energy and reserve markets considering demand response program. J. Clean. Prod. 2018, 186, 293-303. [CrossRef]

9. Ahmadian, A.; Mohammadi-Ivatloo, B.; Elkamel, A. A Review on Plug-In Electric Vehicles: Introduction, Current Status, and Load Modeling Techniques. J. Mod. Power Syst. Clean Energy 2020, 8, 412-425. [CrossRef]

10. Ahmadian, A.; Sedghi, M.; Aliakbar-Golkar, M. Stochastic modeling of plug-in electric vehicles load demand in residential grids considering nonlinear battery charge characteristic. In Proceedings of the 2015 20th Conference on Electrical Power Distribution Networks Conference (EPDC), Zahedan, Iran, 28-29 April 2015; IEEE: Piscataway, NJ, USA, 2015; pp. 22-26.

11. Ahmadian, A.; Sedghi, M.; Aliakbar-Golkar, M.; Elkamel, A.; Fowler, M. Optimal probabilistic based storage planning in tap-changer equipped distribution network including PEVs, capacitor banks and WDGs: A case study for Iran. Energy 2016, 112, 984-997. [CrossRef]

12. Ahmadian, A.; Sedghi, M.; Mohammadi-Ivatloo, B.; Elkamel, A.; Aliakbar Golkar, M.; Fowler, M. Cost-Benefit Analysis of V2G Implementation in Distribution Networks Considering PEVs Battery Degradation. IEEE Trans. Sustain. Energy 2018, 9, 961-970. [CrossRef]

13. Zhou, Y.; Qi, B.; Zhang, B. Online prediction of electrical load for distributed management of PEV based on Grey-Markov model. In Proceedings of the 2017 29th Chinese Control And Decision Conference (CCDC), Chongqing, China, 28-30 May 2017; IEEE: Piscataway, NJ, USA, 2017; pp. 6911-6916.

14. Sun, S.; Yang, Q.; Yan, W. A novel Markov-based temporal-SoC analysis for characterizing PEV charging demand. IEEE Trans. Ind. Informatics 2017, 14, 156-166. [CrossRef]

15. Bremermann, L.E.; Matos, M.; Lopes, J.A.P.; Rosa, M. Electric vehicle models for evaluating the security of supply. Electr. Power Syst. Res. 2014, 111, 32-39. [CrossRef]

16. Li, G.; Zhang, X.-P. Modeling of plug-in hybrid electric vehicle charging demand in probabilistic power flow calculations. IEEE Trans. Smart Grid 2012, 3, 492-499. [CrossRef]

17. Zhou, Z.; Lin, T. Spatial and temporal model for electric vehicle rapid charging demand. In Proceedings of the 2012 IEEE Vehicle Power and Propulsion Conference, Seoul, South Korea, 9-12 October 2012; IEEE: Piscataway, NJ, USA, 2012; pp. 345-348.

18. Mu, Y.; Wu, J.; Jenkins, N.; Jia, H.; Wang, C. A spatial-temporal model for grid impact analysis of plug-in electric vehicles. Appl. Energy 2014, 114, 456-465. [CrossRef]

19. Zeng, F.; Dong, Y.; Tang, J. Feature extraction and severity assessment of partial discharge under protrusion defect based on fuzzy comprehensive evaluation. IET Gener. Transm. Distrib. 2015, 9, 2493-2500. [CrossRef]

20. Wang, D.; Guan, X.; Wu, J.; Gao, J. Analysis of multi-location PEV charging behaviors based on trip chain generation. In Proceedings of the 2014 IEEE International Conference on Automation Science and Engineering (CASE), Taipei, Taiwan, 18-22 August 2014; IEEE: Piscataway, NJ, USA, 2014; pp. 151-156.

21. Panahi, D.; Deilami, S.; Masoum, M.A.S.; Islam, S.M. Forecasting plug-in electric vehicles load profile using artificial neural networks. In Proceedings of the 2015 Australasian Universities Power Engineering Conference (AUPEC), Wollongong, NSW, Australia, 27-30 September 2015; IEEE: Piscataway, NJ, USA, 2015; pp. 1-6.

22. Jahangir, H.; Tayarani, H.; Ahmadian, A.; Golkar, M.A.; Miret, J.; Tayarani, M.; Gao, H.O. Charging demand of Plug-in Electric Vehicles: Forecasting travel behavior based on a novel Rough Artificial Neural Network approach. J. Clean. Prod. 2019, 229, 1029-1044. [CrossRef]

23. Vatanparvar, K.; Faezi, S.; Burago, I.; Levorato, M.; Al Faruque, M.A. Extended range electric vehicle with driving behavior estimation in energy management. IEEE Trans. Smart Grid 2018, 10, 2959-2968. [CrossRef] 
24. Verma, A.; Asadi, A.; Yang, K.; Maitra, A.; Asgeirsson, H. Analyzing household charging patterns of Plug-in electric vehicles (PEVs): A data mining approach. Comput. Ind. Eng. 2019, 128, 964-973. [CrossRef]

25. Zhu, J.; Yang, Z.; Mourshed, M.; Guo, Y.; Zhou, Y.; Chang, Y.; Wei, Y.; Feng, S. Electric Vehicle Charging Load Forecasting: A Comparative Study of Deep Learning Approaches. Energies 2019, 12, 2692. [CrossRef]

26. Moradzadeh, A.; Khaffafi, K. Comparison and evaluation of the performance of various types of neural networks for planning issues related to optimal management of charging and discharging electric cars in intelligent power grids. Emerg. Sci. J. 2017, 1, 201-207.

27. Dai, Y.; Guo, J.; Yang, L.; You, W. A new approach of intelligent physical health evaluation based on GRNN and BPNN by using a wearable smart bracelet system. Procedia Comput. Sci. 2019, 147, 519-527. [CrossRef]

28. Foroughi, M.; Azqhandi, M.H.A.; Kakhki, S. Bio-inspired, high, and fast adsorption of tetracycline from aqueous media using Fe3O4-g-CN@ PEI- $\beta$-CD nanocomposite: Modeling by response surface methodology (RSM), boosted regression tree (BRT), and general regression neural network (GRNN). J. Hazard. Mater. 2020, 388, 121769. [CrossRef] [PubMed]

29. Heydari, A.; Garcia, D.A.; Keynia, F.; Bisegna, F.; De Santoli, L. Renewable energies generation and carbon dioxide emission forecasting in microgrids and national grids using GRNN-GWO methodology. Energy Procedia 2019, 159, 154-159. [CrossRef]

30. Niu, D.; Wang, H.; Chen, H.; Liang, Y. The general regression neural network based on the fruit fly optimization algorithm and the data inconsistency rate for transmission line icing prediction. Energies 2017, 10, 2066.

31. Huang, Y.W.; Chen, M.Q.; Li, Y.; Guo, J. Modeling of chemical exergy of agricultural biomass using improved general regression neural network. Energy 2016, 114, 1164-1175. [CrossRef]

32. Antanasijević, D.; Pocajt, V.; Ristić, M.; Perić-Grujić, A. Modeling of energy consumption and related GHG (greenhouse gas) intensity and emissions in Europe using general regression neural networks. Energy 2015, 84, 816-824. [CrossRef]

33. Li, W.; Yang, X.; Li, H.; Su, L. Hybrid forecasting approach based on GRNN neural network and SVR machine for electricity demand forecasting. Energies 2017, 10, 44. [CrossRef]

34. Wang, Z.; Liu, X.; He, Z.; Su, L.; Lu, X. Intelligent detection of flip chip with the scanning acoustic microscopy and the general regression neural network. Microelectron. Eng. 2019, 217, 111127. [CrossRef]

35. Rentziou, A.; Gkritza, K.; Souleyrette, R.R. VMT, energy consumption, and GHG emissions forecasting for passenger transportation. Transp. Res. Part A Policy Pract. 2012, 46, 487-500. [CrossRef]

36. Moradzadeh, A.; Sadeghian, O.; Pourhossein, K.; Mohammadi-Ivatloo, B.; Anvari-Moghaddam, A. Improving Residential Load Disaggregation for Sustainable Development of Energy via Principal Component Analysis. Sustainability 2020, 12, 3158. [CrossRef]

37. Moradzadeh, A.; Pourhossein, K. Early Detection of Turn-to-Turn faults in Power Transformer Winding: An Experimental Study. In Proceedings of the 2019 International Aegean Conference on Electrical Machines and Power Electronics (ACEMP) \& 2019 International Conference on Optimization of Electrical and Electronic Equipment (OPTIM), Istanbul, Turkey, 27-29 August 2019; IEEE: Piscataway, NJ, USA, 2019; pp. 199-204.

38. Moradzadeh, A.; Mansour-Saatloo, A.; Mohammadi-Ivatloo, B.; Anvari-Moghaddam, A. Performance Evaluation of Two Machine Learning Techniques in Heating and Cooling Loads Forecasting of Residential Buildings. Appl. Sci. 2020, 10, 3829. [CrossRef]

(C) 2020 by the authors. Licensee MDPI, Basel, Switzerland. This article is an open access article distributed under the terms and conditions of the Creative Commons Attribution (CC BY) license (http://creativecommons.org/licenses/by/4.0/). 